\title{
Spatiotemporal dynamics of tuberculosis in East Hararge Zone, Oromiya Region, Ethiopia
}

\author{
Aboma Temesgen Sebu ${ }^{1} \cdot$ Kasahun Takele Genati $^{1} \cdot$ Daniel Biftu Bekalo ${ }^{1} \cdot$ \\ Teshome Kebede Deressa ${ }^{1}$
}

Received: 1 November 2019/Revised: 9 February 2020/ Accepted: 12 February 2020/Published online: 27 February 2020

(C) The Author(s) 2020

\begin{abstract}
Tuberculosis disease burden remains a fundamental global public health concern for decades. The disease may not uniformly distributed with certain geographical areas recording higher notification rate than others. However, the Ethiopian national TB control program does not provide services based on those areas with the greatest notifications but rather on a uniform strategy. Therefore, this study aimed to assess the spatial distribution and presence of the spatio-temporal clustering of the disease in different geographic settings over 8 years in the East Hararge Zone. A retrospective space-time and spatial analysis were carried out at districts of East Hararghe zone based on a total of 34,564 notified TB cases during the study period. The study identified different case notification rate over districts and clustering effects for the purely spatial and spatiotemporal with different estimated relative risks. The study recommends national tuberculosis control program to give attention to highly observed case notification rates specially Babile, Haramaya and Jarso districs of East Hararge Zone to have effective TB intervention in the study area.
\end{abstract}

Keywords TB $\cdot$ Spatiotemporal $\cdot$ Case notification rate

Aboma Temesgen Sebu

aboma.temesgen@gmail.com

1 Department of Statistics, Haramaya University, Dire Dawa, Ethiopia

\section{Introduction}

Tuberculosis is an airborne infectious disease caused by mycobacterium tuberculosis, which has been a global public health concern for decades. Currently, more than 70 species of mycobacterium have been identified many of which are associated with human diseases [1]. There were an estimated 9 million new cases of TB resulting in 1.5 million deaths with the greatest burden of disease in developing nations [2].

Tuberculosis infection is manifested as pulmonary or extra-pulmonary. About $85 \%$ of TB cases are pulmonary while $15 \%$ are extra-pulmonary. Extra-pulmonary TB may involve the spinal cord, kidneys, skin, gastrointestinal tract, lymph nodes, genitourinary system and etc. However, pulmonary TB is much more important because it is the source of infection in the community. Routes of transmission include the inhalation of air when a TB patient coughs, sneezes or spits and use of infected dairy products. The African region, which constitutes 54 countries, contributes $26 \%$ of the global burden of TB making ranked second next to Asia which contributes 59\% of the global case load [3]. Further, the sub-Saharan Africa has continued leading in prevalence and incidence of major infectious disease killers including HIV/AIDS, TB and malaria [4]. Particularly, Ethiopia ranks 3rd in Africa and 8th among the 22 highest TB burdened countries in the world [5].

Regarding to TB distribution in Ethiopia, it is not distributed uniformly with certain regions recording higher notification rates than others. The Ethiopian national TB control program does not provide services based on those areas with the greatest notifications but rather on a uniform strategy. A uniform approach to TB control is not the most effective approach hence the need to have a more in-depth look and design strategies that fits different 
epidemiological patterns and risk factors customized to each region. Studies have suggested problems with treating an entire region with one control strategy, rather than targeting high-risk areas with more effective control measures [6-8].

Research to evaluate the spatial distribution of TB and to identify high risk areas still remains quite limited especially in developing world $[9,10]$. But, research studies on tuberculosis and other vector-borne diseases are a constant concern for health authorities, practitioners, and patients. A variety of environmental, climatic, and socioeconomic factors underlie their spatio-temporal patterns [11]. The geographic information systems used for the studies of such infectious diseases helps to characterize spatio-temporal pattern of the disease dynamics which is vital for its control and prevention strategies. It also helps to control an outbreak of a highly infectious disease in a country, the incidence patterns of spread need to be known. The importance of spatio-temporal modeling of disease surveillance data for the detection of localized outbreaks is increasing. However, a proper understanding of disease dynamics is crucial for monitoring a vaccination program and assessing the risk of future outbreaks [12].

To the best of our knowledge only few studies have analyzed the spatiotemporal dynamics of TB in Ethiopia using district level data and there is no any research study conducted on spatiotemporal dynamics TB in East Hararge Zone. However, there is a need to quantify these differences using appropriate statistical methods, and to detect similar clusters for special implementation of disease control. In addition, some ecological and environmental factors have been reported as being associated with disease occurrence and spatial and temporal patterns of TB notification and the association of those clusters are still unclear. Its also widely known that TB control efforts are best formulated and implemented when areas and time of high notifications are known and well documented. It is equally important to identify period and areas where notification rates are abnormally high given underlying risk factors. This being the fact, this study attempts to examine spatiotemporal dynamics of TB notification using woreda level data and seeks to identify TB hotspot woredas by producing map of clustering observation and fitting appropriate spatiotemporal models for TB cases in the study area.

\section{Method}

\subsection{Study area}

The study was conducted in East Hararge Zone of the Oromia Region, Ethiopia which is found in a complex agro-ecological area with heavy population density, unpredictable rainfall, and significant differences between the agricultural practices within the three main altitude zones create a complicated agricultural profile, and simultaneously support a population that is in general highly vulnerable to food insecurity and disease. It is located 8.8080280 North and 41.6011810 East consisting 18 districts with total catchment area of $26,308 \mathrm{~km}^{2}$ [13]. The map of this study area was provided in Fig. 1.

\subsection{Data collection}

Data collection was made from August 2016 to February 2018 from unit TB registers from all 18 districts that provided Directly Observed Treatment Short-term (DOTS) services from September 2009 to September, 2016 and matched individual cases to their place of districts using codes given by the Central Statistical Agency of Ethiopia (CSA). An address with similar names, but from other locations, was also identified and linked to their true address using location codes. The data collection was carried out using a semi-structured pretested questionnaire by health care workers after four days of practical training. The data were double entered and checked by the principal investigator (PI) and health management information system (HMIS) experts. In addition, the data were checked by year, district and health facilities against unit TB registers for consistency and completeness throughout the entire data collection process.

\subsection{Indicators of spatial autocorrelation}

Spatial autocorrelation identifies the patterns of spatial dependency by calculating the correlation of a variable with itself within a geographic space [14]. The global Morans I statistics were applied to investigate the spatial autocorrelation and distribution pattern of TB in the study area. The value of Morans I is calculated based on the deviation from the mean of two neighboring values [15]. The mathematical formula is as follows.

$I=\frac{n \sum_{i} \sum_{j} w_{i j}\left(x_{i}-\bar{x}\right)\left(x_{j}-\bar{x}\right)}{W \sum_{i}\left(x_{i}-\bar{x}\right)^{2}}$

where $n$ is the sample size, $\bar{x}$ is the mean of the variable, $x_{i}$ is the value of the variable at a particular location $\mathrm{i}, x_{j}$ is the variable value at location $\mathrm{j}$, and $w_{i j}$ is a spatial weight indexing the location of $i$ relative to $j$. The value of Morans I ranges from -1 for negative spatial autocorrelation to 1 for positive spatial autocorrelation. Its significance is evaluated by using a $z$ score and the corresponding $p$ value. The null hypothesis states that there is no spatial autocorrelation for the variable within the geographic area. 


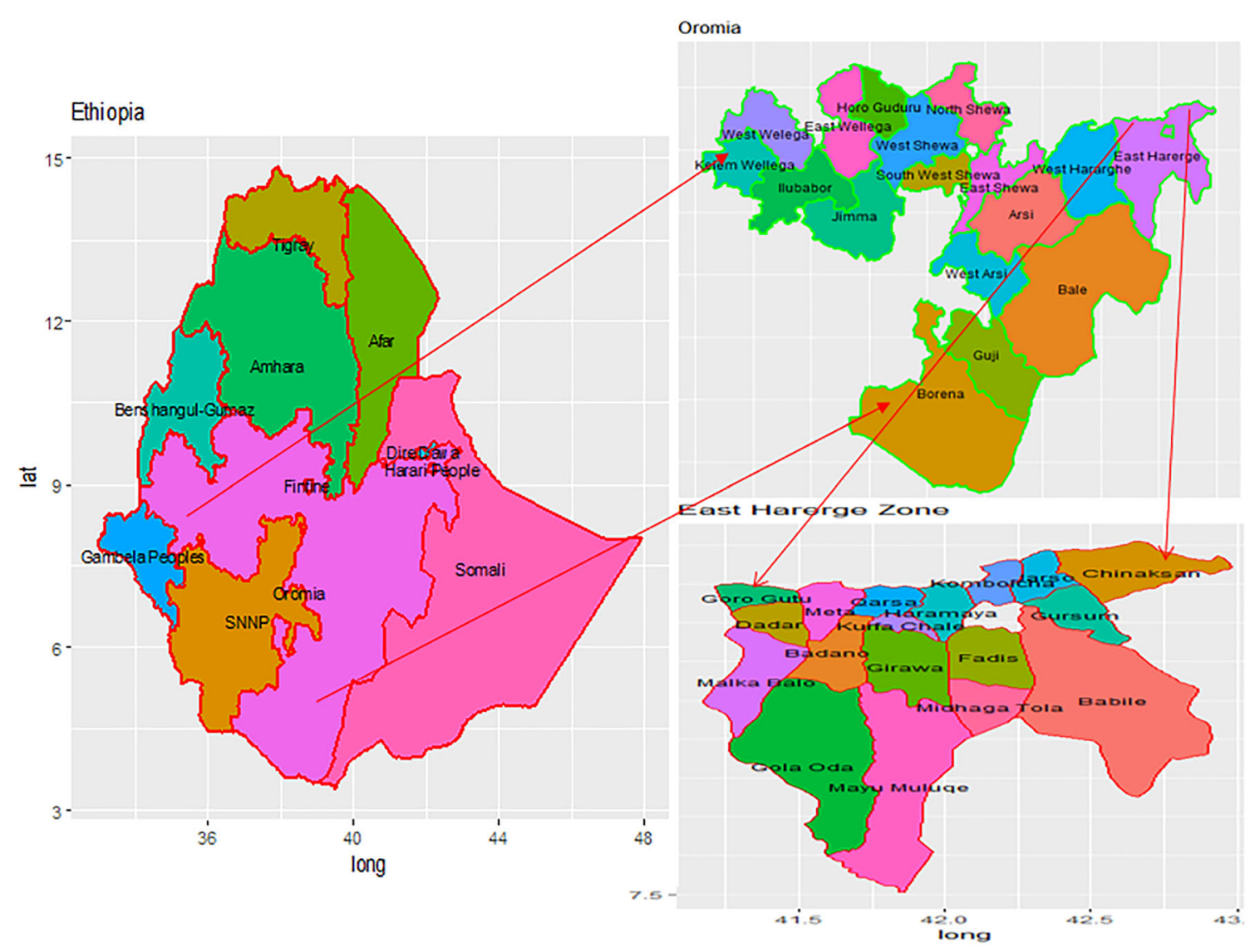

Fig. 1 Map of study area

\subsection{Spatiotemporal analysis}

In this study, a general linear model assuming a Poisson distribution with spatial and temporal random effects will be used to characterize the relationships between TB cases, time and districts. For count data, it is assumed that $n_{i j}$ is the count of TB cases for the $i$ th districts at $j$ th time. There are assumed to be $t$ periods and $\mathrm{m}$ districts. Hence the number of TB cases in each woreda at time, $t$, is Poissondistributed. That is, $y_{i j} \sim \operatorname{Poisson}(\lambda)$ Given $x_{1}, x_{2}, \ldots, x_{m}$ location dependent covariates and $z_{1}, z_{2}, \ldots, z_{t}$ temporally dependent covariates [16]

$P\left(Y=k / x_{1}, x_{2}, \ldots, x_{m}\right)=\frac{e^{\lambda} \lambda^{k}}{k !}$

where $\log (\lambda)=x_{i}^{\prime} \beta+z_{j}^{\prime} \gamma$ Maximum likelihood estimation procedure will be used to estimate the parameters $\beta$ and $\gamma$.

\section{Results and discussion}

\subsection{Description of number of notified smear positive pulmonary TB cases in the districts of East Hararge Zone, 2009-2016}

The summary for the number of notified smear positive pulmonary TB cases in the districts of East Hararge zone (2009-2016) was depicted in Table 1. From this result a total of 34,564 cases were diagnosed and treated during the period from September 2009 to September 2016 in the 18 districts of East Hararge Zone. Of these total cases, 4465 $(12.92 \%)$ were from the Haramaya District, whereas 691 $(2.00 \%$ ) cases were from Mayu Muluqe districts representing the maximum and minimum registered Smear Positive Pulmonary TB cases in zone respectively over 8 years which was considered for the analysis. The yearly distribution of these cases for all years within districts of the zone variations was provided in Table 1.

The yearly total number of TB cases notified and calculated mean for the number of districts in East Hararge zone also depicted in the last row of Table 1. This also showed that the yearly fluctuation of number of TB cases 


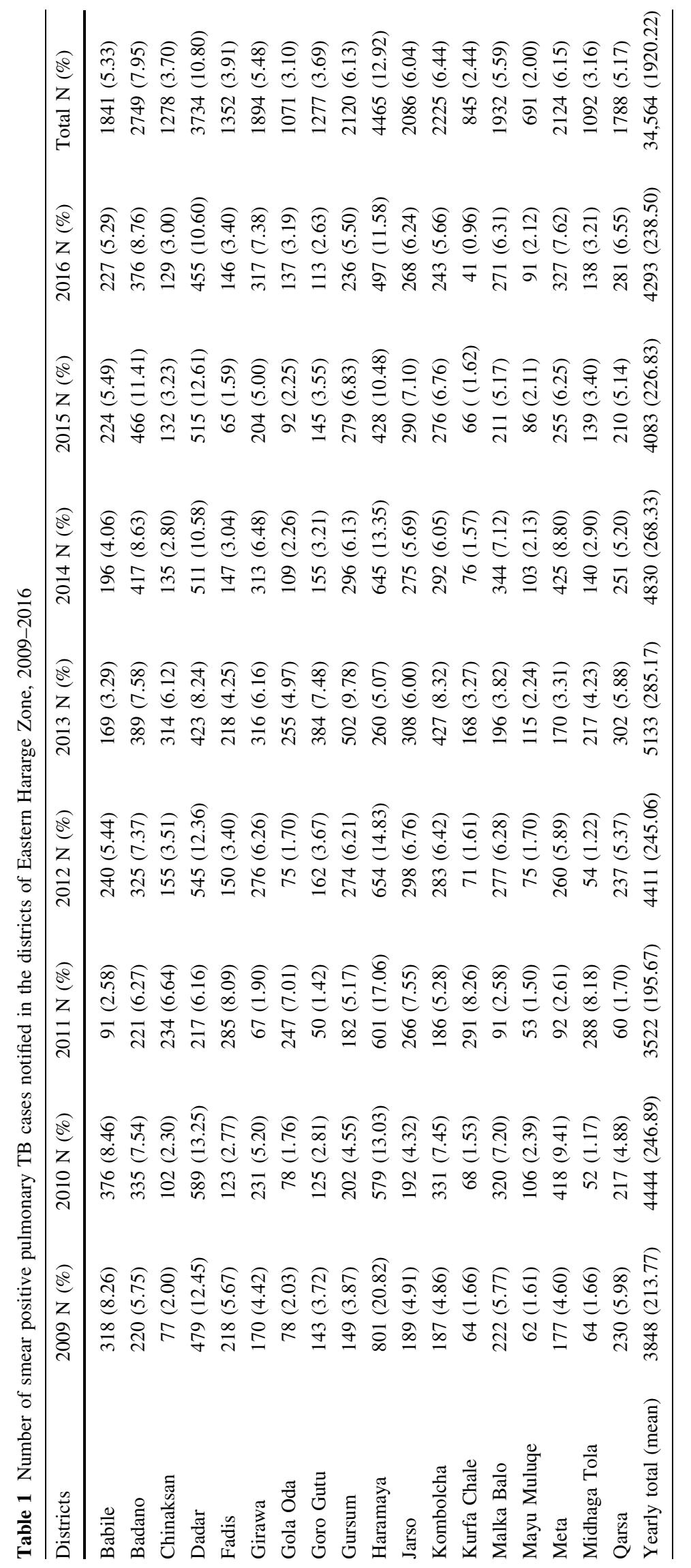


Fig. 2 The yearly distribution map of number of smear positive pulmonary TB cases notified in the districts of Eastern Hararge Zone (2009-2016)

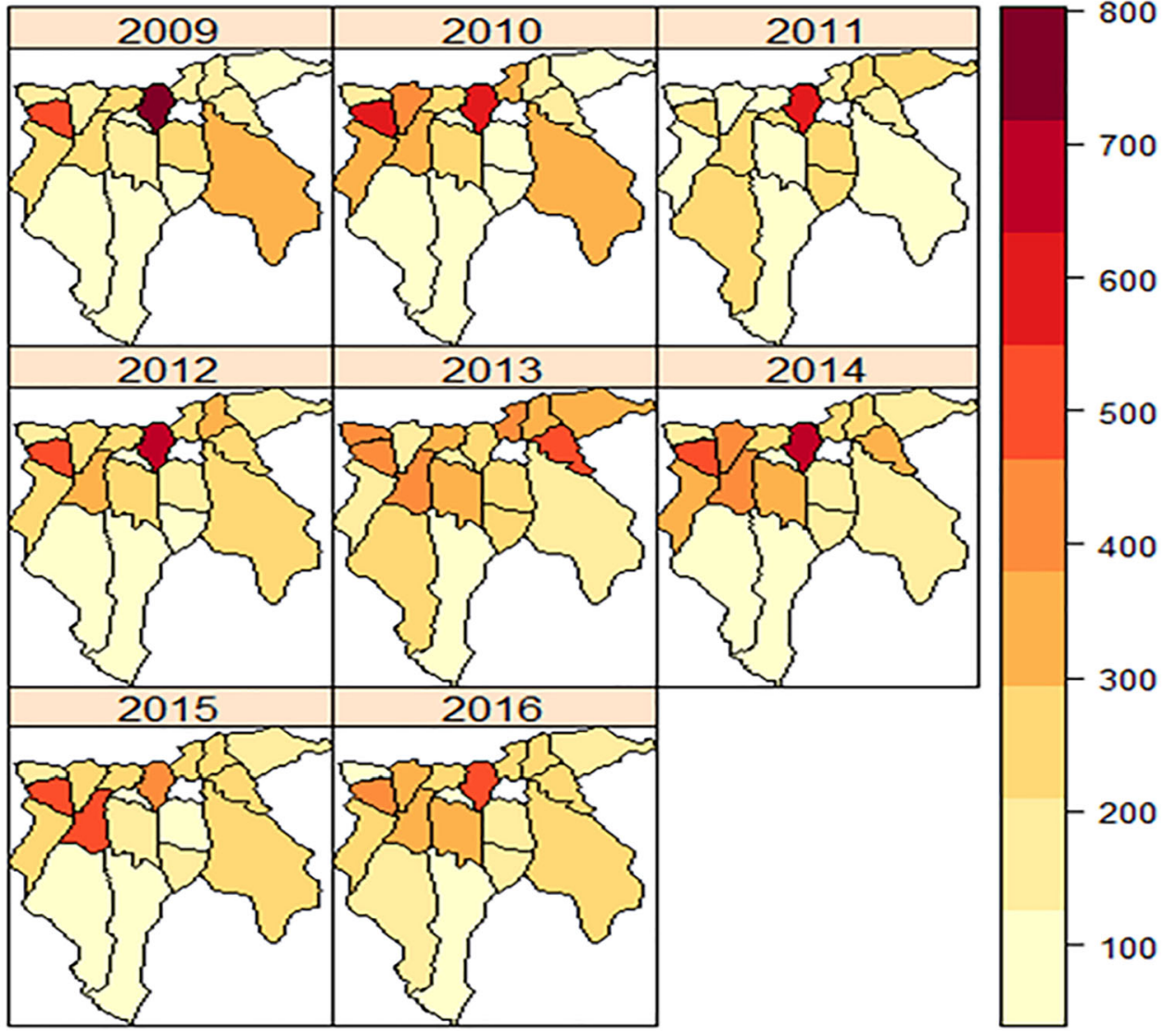

notified lying between 3522 and 5133 which were observed in the year 2011 and 2013 respectively representing the minimum and maximum total observed cases during the study period. After the year 2013 the incidence of number of TB notified cases showed decrement in the years 2014 and 2015 recording 4830 and 4083 total number of TB cases, respectively. The yearly calculated mean value for the total number of TB notified cases also lied between 195.67 and 285.17 representing the minimum and maximum average number TB registered in the year 2011 and 2013 respectively. Regarding the district case of the year 2011 the minimum number of TB registered cases in Goro Gutu, Mayu Muluqe, Qarsa and Girawa were the districts in which less than 70 number TB cases registered whereas in 2013 the maximum number of TB cases were registered in Gursum, Kombolcha and Dadar were districts in which more than 400 number of TB cases were observed.

Regarding the variations of number of TB notified cases in the districts based in Table 1, even if high number of TB notified in Haramaya in 2009, Dadar in 2010 and Qarsa in 2013 these districts have showed decrement in number of TB case trend during the study period. This decrement in number of TB case notification may be due to these districts have access to roads which helps for supplying medical equipments for the TB treatments and comfortable to create awareness in these areas which may helped for the decrement in number of TB cases. Despite to these districts, even if lower number of $\mathrm{TB}$ case were notified in the districts of Badano, Chinaksan, Girawa, Gursum, Jarso, Mayu Muluqe and Midhaga Tola in 2009 which was the begging of the study period these districts showed the increasing in number of TB notification over time. These increment in number of TB case in these districts is due to some of these districts remote areas where there is no access to roads which helps to supply medical treatments for TB which need special attention for reducing the TB disease in these areas.

As presented in Fig. 2 of smear positive pulmonary TB distribution map there was a fluctuations of number of $\mathrm{TB}$ yearly showing higher number of TB notified cases in Haromaya districts throughout the 8 years except for the year 2013 which seems lower in relation with remaining years notified cases. Similarly, lower number of TB notified cases were observed in Golaoda and Mayumuluqe in the except for the year 2011 for Gola Oda which seems higher comparison with other years of study periods. Over the past 8 years of the study period considered the number of TB notified cases were ranged from 800 to 100 which were observed in Haramaya district in 2009 and Kurfachale in 2016 respectively. 
Fig. 3 Distribution of average for number of smear positive pulmonary TB cases notified in the districts of Eastern Hararge Zone, 2009-2016

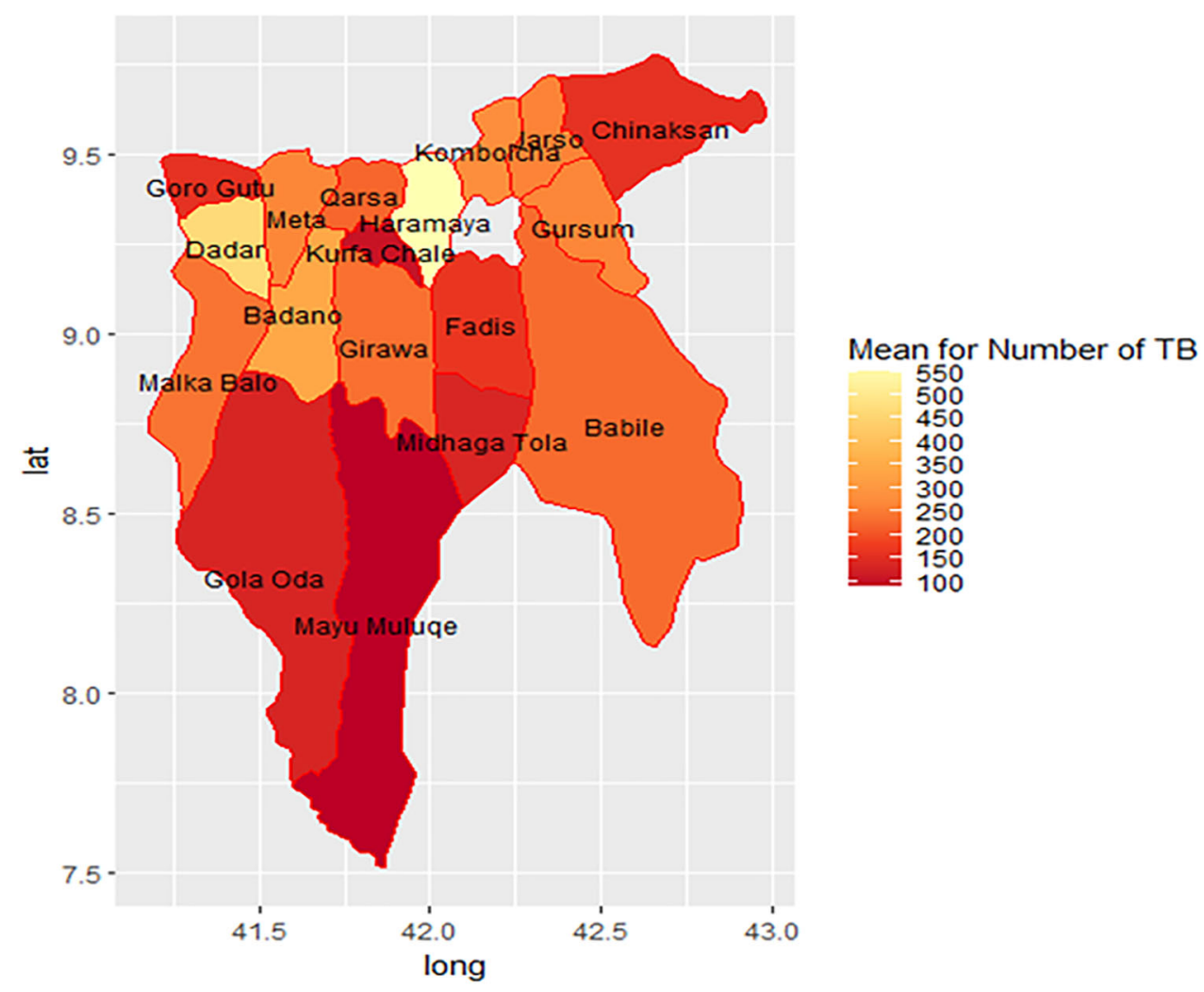

As depicted in Fig. 3 of average number of smear positive pulmonary TB cases notified in the districts of East Hararghe zone (2009-2016). The map indicates the mean number of cases notified ranged between 100 and 550 over the past 8 years study period considered. The map also depicts the larger average number of TB cases notified were in Haramaya and Dadar whereas the lower observed in Mayumuluqe, Gola Oda and Chinaksan in the past 8 years. Furthermore, the average value of the number of TB cases notified over the past 8 years lies between 550 and 50 which were observed in Haramaya and Mayumuluke respectively.

\subsection{Smear positive pulmonary TB case notification rate $(\mathrm{CNR})$ in East Harage Zone}

Table 2 depicted case notification rate of smear positive pulmonary TB cases notified in the districts of East Hararghe Zone (2009-2016) and indicated that more than 200 mean CNR per 100,000 population were observed in Babile, Jarso and Haramaya districs of Eastern Hararghe zone. Similarly,the result indicates yearly fluctuation of CNR trend in the all districts of the Zone. The general CNR distribution shows CNRs varied by district across the years having the mean CNRs ranging from 99 to 246 per 100,000 populations in the past 8 years.
Year total case notification rate (CNR) of TB in East Hararge zone were shown in the last row of Table 2 depicting the yearly fluctuated of total CNR in Zone lies between 2503 and 3887 showing total number of observed TB cases per 100,000 population in the zone which were observed in year 2009 and 2013 respectively representing the minimum and the maximum total CNR during the study period. The total CNR trend also indicated that increment from year 2009 to 2013 and slight decrement before year 2013 to the year 2016 which is the end of the study period. Regarding the mean CNR during the study period, the minimum average CNR (139 TB cases per 100,000 population) were observed in year 2009 whereas the maximum average CNR (216 TB case per 100,000 population) were observed in the year 2013. As elaborated in Table 2 yearly maximum CNR were observed in year 2013 and maximum number of $\mathrm{TB}$ cases were also observed in this year as depicted in the Table 1.

The yearly CNR distribution map of TB cases of Fig. 4 also summarized CNR lying between 50 and 450 showing higher CNR in Haramay and Babile districts in 2009, Babile, Dadar, Harama, kombolcha districst in 2010, Kurfachale, Midhagatola and Chinaksan in 2011, Babile, Haramaya, Jarso in 2013. Similarly, higher CNR were observed in midhaga tola, chinaksan and kombolcha from year 2014 to 2016 and higher CNR were observed in Babile and mayumuleqe districts of the zone (Table 2 and 
Table 2 Case notification rates of smear positive pulmonary TB cases per 100,000 population in the districts of Eastern Hararge Zone, 2009-2016

\begin{tabular}{|c|c|c|c|c|c|c|c|c|c|c|}
\hline \multirow[t]{2}{*}{ Districts } & \multicolumn{8}{|l|}{ Year } & \multirow{2}{*}{$\begin{array}{l}\text { Mean } \\
\text { CNR }\end{array}$} & \multirow[t]{2}{*}{ Population count } \\
\hline & 2009 & 2010 & 2011 & 2012 & 2013 & 2014 & 2015 & 2016 & & \\
\hline Babile & 339 & 401 & 97 & 256 & 180 & 209 & 239 & 242 & 246 & 93,708 \\
\hline Badano & 92 & 140 & 92 & 136 & 163 & 175 & 195 & 157 & 144 & 238,966 \\
\hline Chinaksan & 88 & 117 & 269 & 178 & 361 & 155 & 152 & 148 & 183 & 87,063 \\
\hline Dadar & 198 & 243 & 90 & 225 & 175 & 211 & 213 & 188 & 193 & 242,140 \\
\hline Fadis & 193 & 109 & 252 & 133 & 193 & 130 & 57 & 129 & 149 & 113,108 \\
\hline Girawa & 71 & 96 & 28 & 115 & 132 & 130 & 85 & 132 & 99 & 240,173 \\
\hline Gola Oda & 75 & 75 & 237 & 72 & 244 & 104 & 88 & 131 & 128 & 104,440 \\
\hline Goro Gutu & 99 & 87 & 35 & 113 & 267 & 108 & 101 & 79 & 111 & 143,931 \\
\hline Gursum & 98 & 133 & 120 & 180 & 330 & 195 & 184 & 155 & 174 & 151,931 \\
\hline Haramaya & 296 & 214 & 222 & 241 & 96 & 238 & 158 & 183 & 206 & 271,018 \\
\hline Jarso & 162 & 165 & 228 & 255 & 264 & 236 & 249 & 230 & 224 & 116,638 \\
\hline Kombolcha & 134 & 236 & 133 & 202 & 305 & 208 & 197 & 173 & 199 & 170,816 \\
\hline Kurfa Chale & 109 & 116 & 496 & 121 & 286 & 129 & 112 & 70 & 180 & 140,080 \\
\hline Malka Balo & 125 & 180 & 51 & 156 & 110 & 194 & 119 & 153 & 136 & 58,701 \\
\hline Mayu Muluqe & 134 & 229 & 115 & 162 & 249 & 223 & 186 & 197 & 187 & 177,416 \\
\hline Meta & 70 & 166 & 36 & 103 & 67 & 168 & 101 & 130 & 105 & 252,269 \\
\hline Midhaga Tola & 85 & 69 & 383 & 72 & 289 & 186 & 185 & 184 & 182 & 46,210 \\
\hline Qarsa & 135 & 127 & 35 & 139 & 177 & 147 & 123 & 165 & 131 & 75,201 \\
\hline $\begin{array}{l}\text { Yearly total } \\
\text { (mean) }\end{array}$ & $\begin{array}{l}2503 \\
(139)\end{array}$ & $\begin{array}{l}2903 \\
(161)\end{array}$ & $\begin{array}{l}2918 \\
(162)\end{array}$ & $\begin{array}{l}2859 \\
(159)\end{array}$ & $\begin{array}{l}3887 \\
\quad(216)\end{array}$ & $\begin{array}{l}3147 \\
(175)\end{array}$ & $\begin{array}{l}2743 \\
(152)\end{array}$ & $\begin{array}{l}2846 \\
(158)\end{array}$ & $\begin{array}{l}2976 \\
(165)\end{array}$ & $\begin{array}{r}2,723,809 \\
(151,323)\end{array}$ \\
\hline
\end{tabular}

Fig. 3). Wang et al. [17] on their study of the spatial epidemiology of tuberculosis in Linyi, Chine from 2005 to 2010 and found TB case notification rate lying between 27.20 and 100.58 in Linyi city of China which is smaller TB case notified rates in compared to this study case notified rates. Figure 5 summarizes the yearly CNR distribution of TB cases. It shows that the yearly CNR distribution of TB cases were between 50 and 450 showing higher CNR in Haramaya and Babile districts in 2009. In addition, higher CNR were observed in Babile, Haramaya and Kombolcha districts in 2010, kurfachale,Midhagetola and chinaksan in 2011 while in 2013 in Babile, Haramaya and Jarso.

Regarding minimum observed CNR during study period, in 2009 the minimum CNR rate were observed in Meta,Girawa and Gola Oda, in 2010 in districts of Midhaga Tola and Gola oda, in 2011 in districts of Goro Gutu,Qarsa, Meta and Malka Balo, in 2012 in districts of Gola Oda and Midhaga Tola, in 2013 only in Meta district, in 2015 in districts of Fadis and Girawa, and in 2016 in the districts of Goro Gutu and Kurfa Chale were the districts in which minimum CNRs registered for different years during the study period as depicted in Table 2 and Fig. 4.
The calculate average case notified rate for the past 8 years of study period was depicted in Fig. 5 below. The figure shows the average CNR ranges between 100 and 240 per 100,000 population in districts of East Hararghe Zone. Specific to each districts of the zone, the higher average CNR were observed in Babile, Jarso, Kombolcha, Haramaya, Dadar and Mayumuluqe districts of the zone whereas the lower value were obtained for Gorogutu, Meta and Girawa districts.

\subsection{Spatial distribution and spatial clustering of smear-positive pulmonary TB at the districts of East Hararge Zone}

Table 3 explained the spatial autocorrelation analysis and spatial clustering of pulmonary TB in the East Hararge Zone. The Global Morans I autocorrelation analysis showed that smear-positive PTB was significantly autocorrelated for all years considered in the study as well as for the mean values of number of TBs notified in the past 8 years of study period considered (Table 3 ). The calculated Moran'I was positive for all years considered for the study implying there was positive spatial autocorrelation between the nearing districts which depicts that the nearing districts 
Fig. 4 Case notification rate of smear positive pulmonary TB per 100,000 population in the districts of East Hararge Zone, 2009-2016

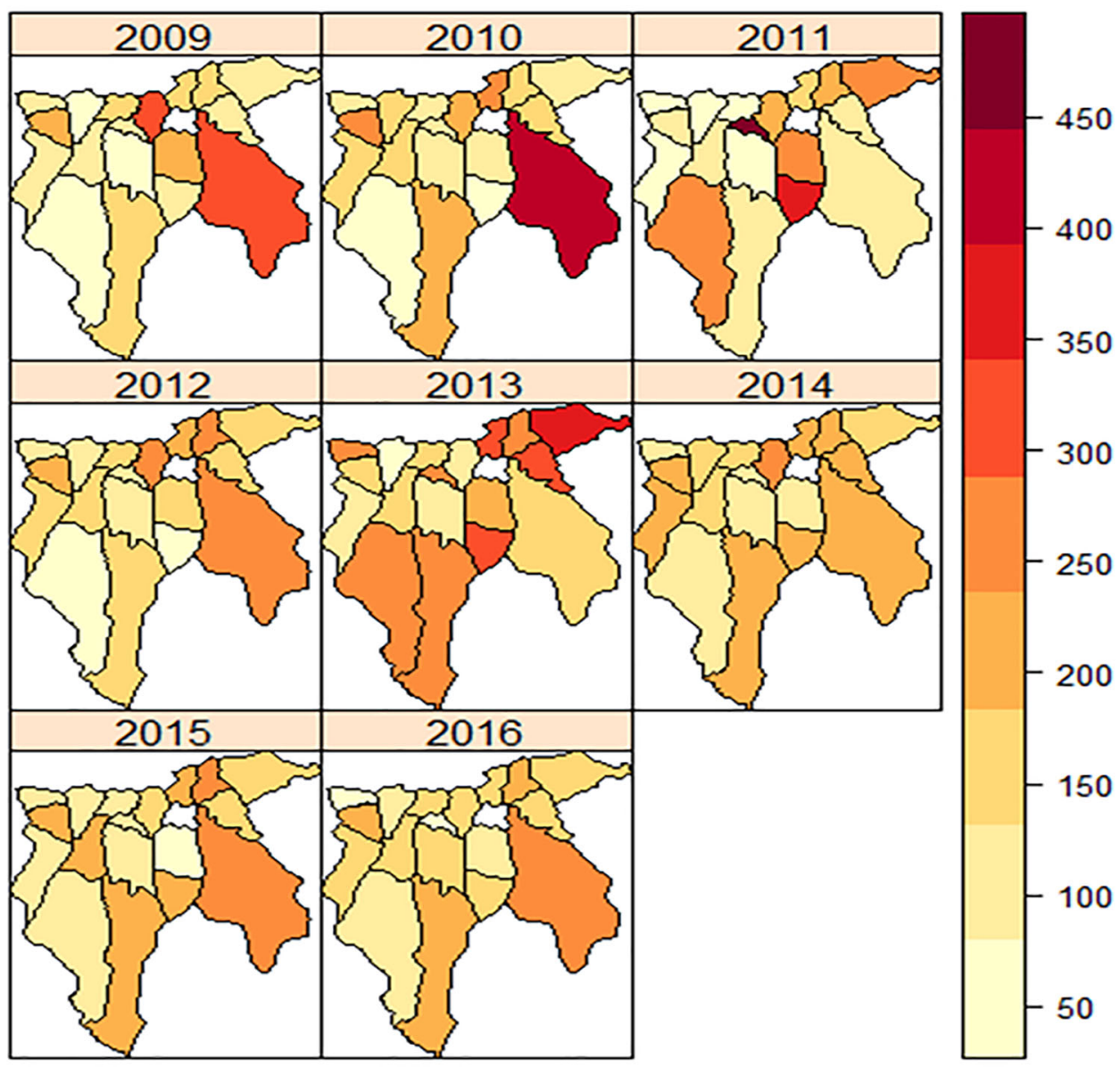

are likely to be clustered. The Moran's Z-score was also obtained from its expected value and the variance and it was the ratio of the difference between the calculated Moran's I and its expected value divided by the standard deviation (square root of variance). Dangisso et al. [18] on the study of spatio-temporal analysis of smear-positive tuberculosis in the Sidama Zone of Southern Ethiopia and Zhao et al. [19] on the study of space-time clustering characteristics of tuberculosis in China found that positive significant of global Moran's I autocorrelation for the yearly distribution of TB.

Table 4 depicted the purely spatial analysis and this table also provided observed and expected number of cases, likely hood ratio (LLR) and the relative risk (RR). The relative risk (RR) provided in this table indicates the ration of estimated risk within the cluster divided by the estimated risk outside the specified cluster. The result also identified 9 different clusters with different estimated significant relative risks (RR). Accordingly, the first cluster which was considered most likely cluster for a high occurrence of smear-positive PTB consisted of 9 districts with a total of 17,304 notified cases during 2009-2016 with estimated RR 1.46 showing the risk TB cases within this cluster was $46 \%$ higher in comparison with risk of the

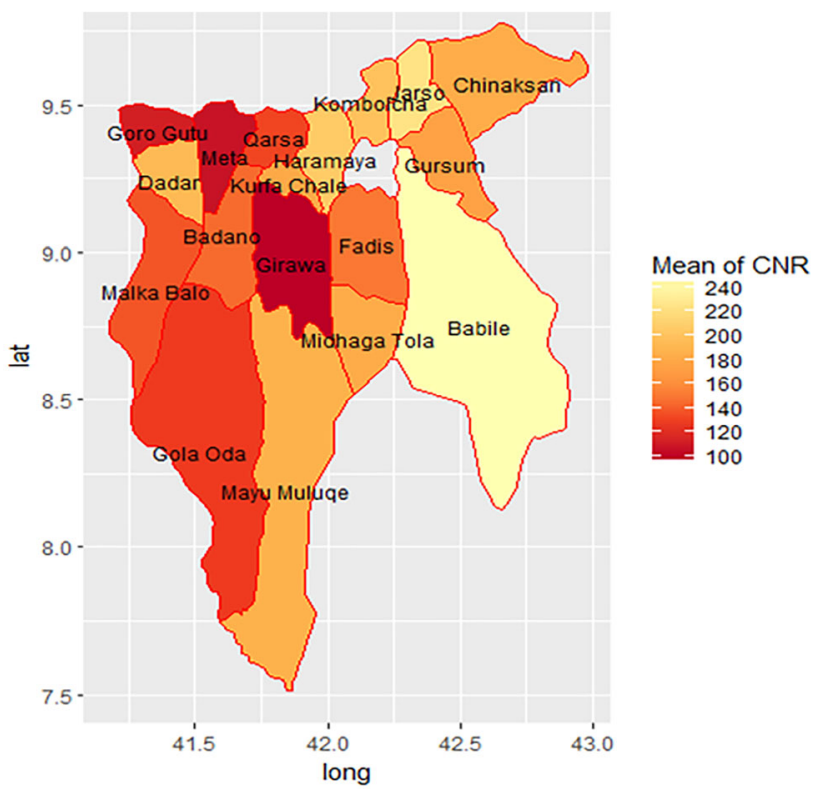

Fig. 5 The mean CNR of smear positive pulmonary TB per 100,000 population in East Hararghe Zone, 2009-2019

cases outside this cluster. The second cluster also 2 districts with a total of 4311 observed cases notified during 
Table 3 Spatial autocorrelations smear positive pulmonary TB cases in Eastern Hararge Zone, 2009-2016

\begin{tabular}{|c|c|c|c|c|c|}
\hline Year & Moran's I & Expected & Variance & Z-score & $p$ value \\
\hline 2009 & 0.474515 & -0.05882 & 0.031996 & 2.98162 & 0.001434 \\
\hline 2010 & 0.449658 & -0.05882 & 0.039166 & 2.56933 & 0.005095 \\
\hline 2011 & 0.355249 & -0.05882 & 0.035346 & 2.20245 & 0.01382 \\
\hline 2012 & 0.522338 & -0.05882 & 0.039289 & 2.93198 & 0.001684 \\
\hline 2013 & 0.36247 & -0.05882 & 0.037142 & 2.18599 & 0.01441 \\
\hline 2014 & 0.476207 & -0.05882 & 0.039231 & 2.70126 & 0.003454 \\
\hline 2015 & 0.558412 & -0.05882 & 0.039445 & 3.10780 & 0.000942 \\
\hline 2016 & 0.429856 & -0.05882 & 0.039516 & 2.45831 & 0.00698 \\
\hline Average & 0.502676 & -0.05882 & 0.039228 & 2.83499 & 0.002291 \\
\hline
\end{tabular}

Table 4 Purely spatial clusters of TB cases detected by purely spatial analysis in the Eastern Hararge Zone, 2009-2016

\begin{tabular}{lllcllll}
\hline Cluster & Year & Number of cluster & Observed & Expected & LLR & RR & $p$ value \\
\hline 1 & $2009-2016$ & 9 & 17,304 & $14,053.05$ & 622.4207 & 1.46 & $<0.001$ \\
2 & $2009-2016$ & 2 & 4311 & 3257.64 & 172.3612 & 1.37 & $<0.001$ \\
3 & $2009-2016$ & 1 & 1841 & 1189.12 & 159.2233 & 1.58 & $<0.001$ \\
4 & $2009-2016$ & 1 & 4465 & 3439.11 & 156.8246 & 1.34 & $<0.001$ \\
5 & $2009-2016$ & 1 & 3734 & 3072.66 & 73.54702 & 1.24 & $<0.001$ \\
6 & $2009-2016$ & 2 & 3398 & 3032.73 & 23.28692 & 1.13 & $<0.001$ \\
7 & $2009-2016$ & 1 & 1092 & 954.27 & 9.775591 & 1.15 & $<0.001$ \\
8 & $2009-2016$ & 1 & 691 & 586.39 & 8.982912 & 1.18 & $<0.001$ \\
9 & $2009-2016$ & 1 & 845 & 744.89 & 6.592712 & 1.14 & 0.011 \\
\hline
\end{tabular}

2009-2016 with an estimated RR of 1.37 showing the risk of the TB cases in this cluster was $37 \%$ higher than that estimated risks outside this cluster. The most likely clusters (cluster) were detected in Chinaksan, Gursum, Jarso, Kombolcha, Babile, Haramaya, Midhaga Tola and Kurfa Chale districts whereas some others districts were also detected in some secondary clusters as depicted in Table 4 and Fig. 6. When we compare the estimated risks of the 9 clusters the third cluster has higher risk than the remaining clusters having estimated risk ratio of 1.58 showing the risk of TB cases in this cluster was 58\% higher than the estimated risk outside this cluster as depicted in Table 4.

As depicted in Fig. 6 the pattern and instability of spatial clusters in each year during the study period, and the clusters were varying in all districts. The clusters were detected in the Haramaya, Babile, Dadar, Fadis and Jarso districts for 1-5 respectively in 2009. In 2010 four cluster locations were detected consisting Babile, Dadar and Mayu Muluqe districts for cluster 1, 3 and 4 respectively whereas the third cluster considers Kombolcha, Haramaya and Jarso districts. Similarly, in 2011 most likely cluster detected 9 locations with estimated RR 3.22 with 2424 observed cases

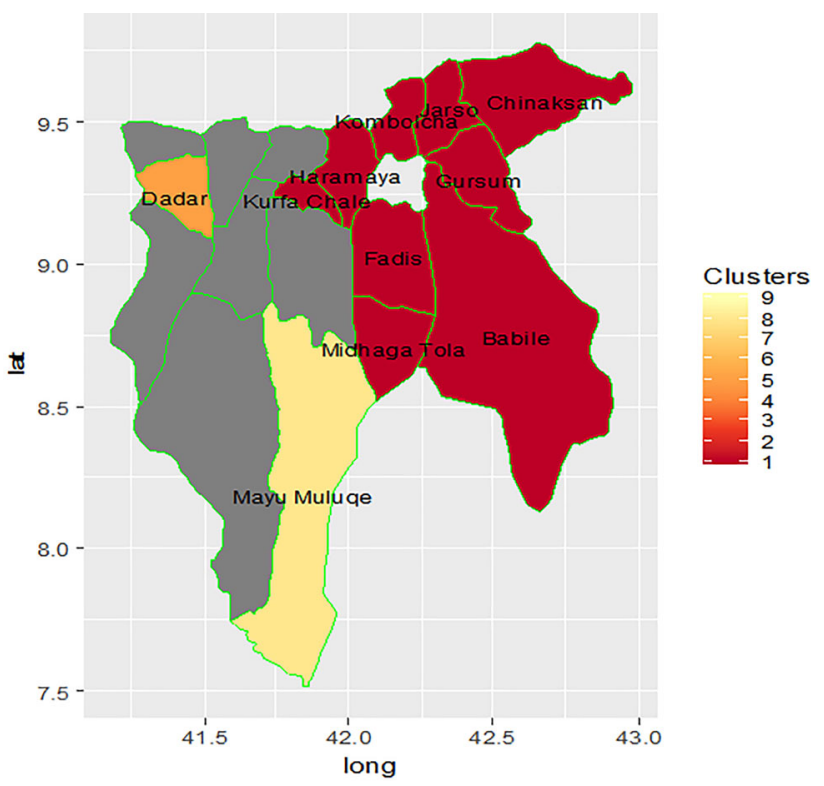

Fig. 6 Purely spatial clusters of smear positive pulmonary TB in Eastern Hararge Zone, 2009-2016

in comparison with 1431 expected cases the this cluster includes Chinaksan, Gursum, Jarso, Kombolcha, Babile, 
Table 5 Space time clustering analysis of smear positive pulmonary TB in the districts of Eastern Hararge Zone, 2009-2016

\begin{tabular}{llllllll}
\hline Clusters & Data year & Number of cluster & Observed & Expected & LLR & RR & $p$ value \\
\hline 1 & $2011-2014$ & 9 & 9388 & 7026.53 & 462.88 & 1.46 & 0.001 \\
2 & $2009-2012$ & 3 & 3873 & 3175.79 & 79.28 & 1.25 & 0.001 \\
3 & $2012-2015$ & 1 & 1994 & 1536.33 & 65.44 & 1.32 & 0.001 \\
4 & 2011 & 3 & 588 & 358 & 62.54 & 1.65 & 0.001 \\
5 & 2013 & 1 & 384 & 228.15 & 44.43 & 1.69 & 0.001 \\
6 & $2014-2015$ & 1 & 883 & 757.58 & 10.09 & 1.17 & 0.006 \\
\hline
\end{tabular}

Fadis, Haramaya, Midhaga Tola and Kurfa Chale. Furthermore, eight cluster locations with estimated RR of 1.25 with 1884 observed cases comparison with 1652 expected cases were detected for Chinaksan, Gursum, Jarso, Kombolcha, Babile, Fadis, Haramaya and Midhaga Tola districts of East Hararghe Zone. Similar, study was conducted Dangisso et al. [18] on spatio-temporal analysis of smear positive tuberculosis in the Sidama zone, Southern Ethiopia and detected seven most likely and secondary spatial clusters of smear-positive pulmonary tuberculosis cases using purely spatial analysis.

In a space-time cluster analysis of smear-positive pulmonary TB during 2009-2016, we found the most likely clusters (cluster 1) at 9 district locations with estimated RR 1.46 with 9388 observed and 7026 expected cases depicting the estimated risk of this cluster was $46 \%$ greater than that of estimated risk outside this cluster. The locations for space-time clusters were the same with the locations in which the purely spatial clusters were detected, except for the secondary clusters. We also identified the secondary space-time cluster in 3 locations $(\mathrm{RR}=1.25, p=0.001$ ) with 3873 observed in comparison with 3175 expected cases in time frame 2009-2012 (Table 5 and Fig. 7). Similar study conducted in different countries such as Lima et al. [20], Dangisso et al. [18] and Zhao et al. [19] detected different cluster locations with estimated significant risk ratio on their space time cluster analysis. Recently Shaweno et al. [21] also tried to spatiotemporal effects of TB on their of heterogeneity of distribution of tuberculosis in Sheka Zone of Ethiopia and the study left in detecting different cluster location in which this study mainly focused on Ethiopia.

This study was limited to spatiotemporal dynamics of TB based on true CNRs since cases were linked to their districts; in addition, cases that were registered outside the study area (nearby areas) were also linked to their actual address in the study area. We used the districts as a unit of analysis which helped in improving our understanding of the spatial epidemiology of the disease in a wider geographic context. The long study period ( 8 years) enabled us to assess the spatial pattern and stability of clusters of the disease in the study area. We also recommend future

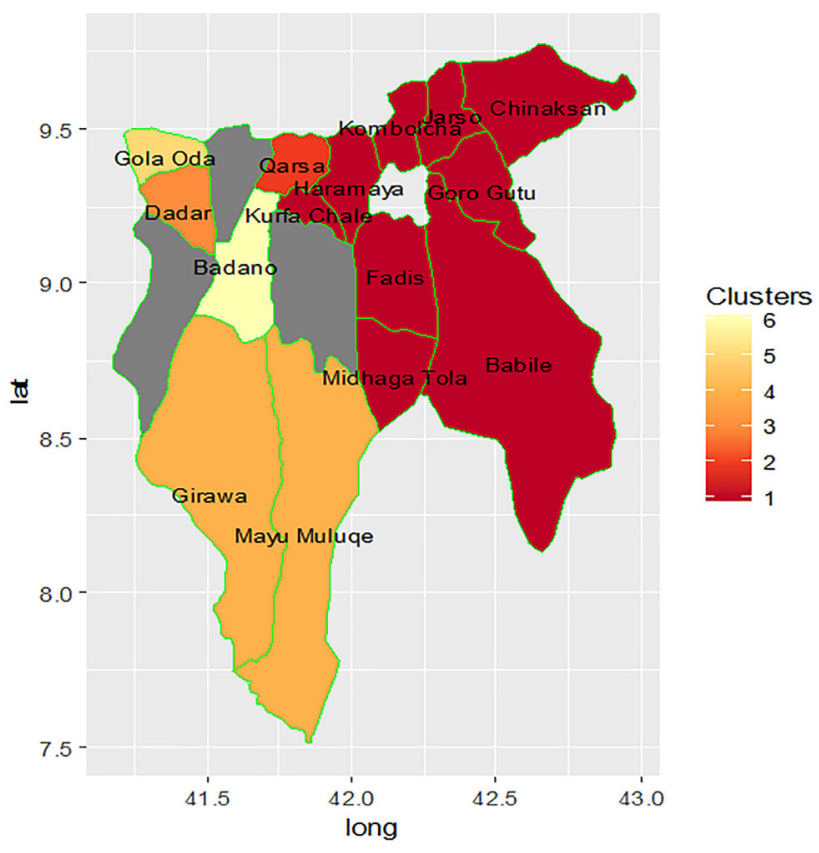

Fig. 7 Space time clusters of smear positive pulmonary TB in the districts of Eastern Hararge Zone, 2009-2016

coming researchers to consider other socioeconomic factors which affects the TB distribution in the study areas.

\section{Conclusion}

This study investigated spatio-temporal clusters and spatial variations of smear-positive PTB in the East Hararghe Zone. The results of the study showed TB in the study area did not uniformly occur in different geographic areas, and exhibited a non-random distribution.

The government and other concerned body should give special attentions to Badano, Chinakstan, Gursum, Mayu, Girawa and Midhaga Tola districts because the number of TB notified cases were increasing over time in these areas which needs interventions for minimizing the number of TB cases.

This study may guides TB control programs to devise effective TB control strategies for the districts highly 
exposed to highest CNRs specially Babile, Jarso and Haramaya districts of East Hararghe Zone. Further investigations based on individual level locations are needed to identify the presence of localized spatial clustering and causes for unusually high rates in those areas by incorporating socioeconomic factors, type of TB strain and access to health services so as to improve our understanding of the possible causes for unusually high disease rates.

Acknowledgements We would like to thank East Hararghe Zone Districts for providing us the data used for this study and Haramaya University Research Office for giving us this opportunities to conduct this research.

Open Access This article is licensed under a Creative Commons Attribution 4.0 International License, which permits use, sharing, adaptation, distribution and reproduction in any medium or format, as long as you give appropriate credit to the original author(s) and the source, provide a link to the Creative Commons licence, and indicate if changes were made. The images or other third party material in this article are included in the article's Creative Commons licence, unless indicated otherwise in a credit line to the material. If material is not included in the article's Creative Commons licence and your intended use is not permitted by statutory regulation or exceeds the permitted use, you will need to obtain permission directly from the copyright holder. To view a copy of this licence, visit http://creativecommons. org/licenses/by/4.0/.

\section{References}

1. Murray, B. (2002). Molecular epidemiology and the dynamics of tuberculosis transmission among foreign-born people. Canadian Medical Association Journal, 167(4), 355-356.

2. WHO (2014). Global tuberculosis control. Surveillance, planning and financing. Switzerland.

3. WHO (2012). Tuberculosis fact sheet no. 104, Geneva.

4. Mboowa, G. (2014). Genetics of sub-Saharan African human population: implications for HIV/AIDS, tuberculosis, and malaria. International Journal of Evolutionary Biology, 2014, $1-8$.

5. WHO (2009). Global tuberculosis control WHO report epidemiology, strategy, financing. Ginebra (Suiza): Global Tuberculosis Programme.

6. Anselin, L. (2010). Local indicators of spatial association-LISA. Geographical Analysis, 27(2), 93-115.
7. Assuno, R., Barreto, S., Guerra, H., \& Sakurai, E. (1998). Mapas de taxas epidemiolgicas: uma abordagem Bayesiana. Cadernos de Sade Pblica, 14(4), 713-723.

8. Gatrell, A., \& Bailey, T. (1996). Interactive spatial data analysis in medical geography. Social Science and Medicine, 42(6), 843-855.

9. Verver, S., Warren, R., Munch, Z., et al. (2004). Transmission of tuberculosis in a high incidence urban community in South Africa. International Journal of Epidemiology, 2004(33), 351-57.

10. Vieira, R., Prado, T., Siqueira, M., et al. (2008). Diet Spatial distribution of new tuberculosis cases in Vitria, State of Esprito Santo, between 2000 and 2005. Revista da Sociedade Brasileira de Medicina Tropical, 41(1), 82-86.

11. Lpez-Qulez, A. (2019). Spatio-temporal analysis of infectious diseases. International Journal of Environmental Research and Public Health, 16(4), 669.

12. Sharmin, S., \& Rayhan, M. (2012). Spatio-temporal modeling of infectious disease dynamics. Journal of Applied Statistics, 39(4), 875-882.

13. BoFED (Bureaue of Finance Economic Development) (2008). Socioeconomic profile of Oromia. Finfinne, Ethiopia.

14. Cliff, A., \& Ord, J. (1981). Spatial processes. London: Pion Limited.

15. Moran, P. (1950). Notes on continuous stochastic phenomena. Biometrika, 37(1/2), 17.

16. Nakaya, T., Fotheringham, A., Brunsdo, C., et al. (2005). Geographically weighted Poisson regression for disease association mapping. Statistics in Medicine, 24(17), 695-2717.

17. Wang, T., Xue, F., Chen, Y., et al. (2012). The spatial epidemiology of tuberculosis in Linyi City, China, 2005-2010. BMC Public Health, 12(1), 885.

18. Dangisso, M., Datiko, D., \& Lindtjrn, B. (2015). Spatio-temporal analysis of smear-positive tuberculosis in the Sidama Zone, southern Ethiopia. PLoS ONE, 10(6), e0126369.

19. Zhao, F., Cheng, S., Huang, F., et al. (2013). Space-time clustering characteristics of tuberculosis in China, 2005-2011. PLoS ONE, 8(12), e83605.

20. Lima, S., dos Santos, A., Duque, A., et al. (2019). Spatial and temporal analysis of tuberculosis in an area of social inequality in Northeast Brazil. BMC Public Health, 19(1), 2019.

21. Shaweno, D., Shaweno, T., Trauer, J., et al. (2017). Heterogeneity of distribution of tuberculosis in Sheka Zone, Ethiopia: Drivers and temporal trends. The International Journal of Tuberculosis and Lung Disease, 21(1), 79-85.

Publisher's Note Springer Nature remains neutral with regard to jurisdictional claims in published maps and institutional affiliations. 